\title{
PERSPECTIVE
}

\section{Prioritised research agenda for prevention and control of chronic respiratory diseases}

\author{
J. Bousquet, J. Kiley, E.D. Bateman, G. Viegi, A.A. Cruz, N. Khaltaev, N. Aït Khaled, \\ C.E. Baena-Cagnani, M.L. Barreto, N. Billo, G.W. Canonica, K-H. Carlsen, \\ N. Chavannes, A. Chuchalin, J. Drazen, L.M. Fabbri, M.W. Gerbase, M. Humbert, \\ G. Joos, M.R. Masjedi, S. Makino, K. Rabe, T. To and L. Zhi
}

ABSTRACT: The 2008-2013 World Health Organization (WHO) action plan on noncommunicable diseases (NCDs) includes chronic respiratory diseases as one of its four priorities. Major chronic respiratory diseases (CRDs) include asthma and rhinitis, chronic obstructive pulmonary disease, occupational lung diseases, sleep-disordered breathing, pulmonary hypertension, bronchiectiasis and pulmonary interstitial diseases. A billion people suffer from chronic respiratory diseases, the majority being in developing countries. CRDs have major adverse effects on the life and disability of patients. Effective intervention plans can prevent and control CRDs, thus reducing morbidity and mortality. A prioritised research agenda should encapsulate all of these considerations in the frame of the global fight against NCDs. This requires both CRD-targeted interventions and transverse NCD programmes which include CRDs, with emphasis on health promotion and disease prevention.

KEYWORDS: Asthma, chronic obstructive pulmonary disease, chronic respiratory diseases, noncommunicable diseases, prevention, research

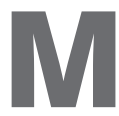
ajor chronic respiratory diseases (CRDs) include asthma and rhinitis, chronic obstructive pulmonary disease (COPD), occupational lung diseases, sleep-disordered breathing (SDB), pulmonary hypertension, bronchiectiasis and pulmonary interstitial diseases [1].

Over 1 billion people of all ages suffer from CRDs (table 1). Over 500 million of these live in lowand middle-income countries (LMICs). CRDs are increasing in prevalence and severity [1].

CRDs have major adverse effects on the life and disability of patients [1]. It is estimated that 4 million people died prematurely from CRDs in 2005 and it is projected that, globally, the CRD death rate and burden will considerably increase in the future [2].

Everyone in the world is exposed to CRD risk factors, and effective preventive measures are available to reduce the deleterious impact of CRD risk factors: tobacco smoking in all countries, indoor air pollution and particularly biomass fuel combustion in LMICs, outdoor air pollution, unhealthy diet, lack of physical activity and obesity, allergens, and occupational agents $[1,3,4]$. The consequences of these factors start before birth and continue throughout life [5-7]. Many of them are common to other noncommunicable diseases (NCDs) [2]. Furthermore, in some countries, infectious diseases (including tuberculosis and HIV/ AIDS) add to the burden of CRD morbidity. Effective interventions can control CRD and reduce morbidity and mortality.

Most CRDs occur in LMICs, which requires consideration of the following factors. 1) Data on CRD burden and risk factors are scarce and surveillance of CRDs is unavailable in most LMICs. Consequently, the true CRD burden on health services and society is unknown. 2) Infrastructure and programmes for the management of CRDs in many LIMCs are not available or poorly developed because of competing priorities. Resources are limited and fragmented. 3) Facilities for diagnosis and monitoring as well as essential medicines for treating CRDs are not available and/or affordable in many LMICs $[8,9]$. 4) Strategies for CRD prevention and health promotion are often absent or rudimentary. 5) Programmes for educating healthcare providers (HCPs) in the care and management of patients with CRDs require strengthening. 6) Patient involvement in health promotion programmes is rare or non-existent. A
AFFILIATIONS

A full list of the authors' affiliations can be found in the

Acknowledgements section.

CORRESPONDENCE

J. Bousquet

Service des Maladies Respiratories Hopital Arnaud De Villeneuve 34295 Montpellier cedex 5 France

E-mail: jean.bousquet@inserm.fr

Received

Jan 252010

Accepted after revision:

March 012010

First published online:

March 112010 


\begin{tabular}{lc}
\hline TABLE 1 & $\begin{array}{l}\text { Estimated prevalence of chronic respiratory } \\
\text { diseases (CRDs) }\end{array}$ \\
\hline CRD & Prevalence \\
\hline Asthma & 300 million \\
COPD & 210 million \\
Rhinitis (excluding asthma) & 400 million \\
Sleep-disordered breathing & $>100$ million \\
Other CRDs & $>50$ million \\
\hline
\end{tabular}

2007 World Health Organization estimates [1]. COPD: chronic obstructive pulmonary disease.

prioritised research agenda should encapsulate all of these considerations in the frame of the global fight against NCDs. This requires both CRD-targeted interventions, and transverse NCD programmes that address CRDs and health promotion to prevent them.

Among the CRDs, there are currently four major topics for which more research is needed: 1) severe/uncontrolled asthma and comorbidities; 2) COPD and comorbidities; 3) SDB, links with obesity and other NCDs; and 4) early determinants of respiratory diseases.

\section{REVIEW OF SUCCESSFUL INTERVENTIONS \\ Asthma}

\section{Successful interventions in developed countries}

The implementation of clinical practice guidelines has led to improvements in the quality of care and reductions in the burden of disease $[10,11]$. Patient education improves asthma control, reduces urgent care visits and improves quality of life $[12,13]$. Environmental control may improve asthma control [14] but single intervention measures are not effective [15].

\section{Successful interventions in LMICs}

Outdoor air pollution may be controlled, thus reducing asthma severity [16]. For LMICs, The International Union Against Tuberculosis and Lung Disease has developed a guide for asthma management focusing on the World Health Organization (WHO) list of essential medicines [17]. A study in a limited number of patients in LMICs has shown benefits [18] and a systematic approach to the organisation of standard case management has been proposed [19].

\section{Community-wide programmes}

There are limited data on the effectiveness of asthma care in whole populations at the community level. However, there was a considerable cost-effective reduction of hospitalisations and deaths in a study from Finland [20]. In middle-income countries and deprived populations, availability of effective drugs and education reduced hospitalisations and was cost-effective [21-23].

\section{COPD and comorbidities}

\section{Successful interventions in developed countries}

Several guidelines are available for COPD management [24, 25]. However, they should be adapted for LMICs [26]. Environmental control is essential, in particular for tobacco (active and passive smoking, as well as other forms of tobacco) [27-30].
There are several key actions targeting tobacco control such as the WHO Framework Convention on Tobacco Control and the MPOWER package of interventions (monitor tobacco use and prevention policies; protect people from tobacco smoke; offer help to quit tobacco use; warn about the dangers of tobacco; enforce bans on tobacco advertising, promotion and sponsorship, and; raise taxes on tobacco) [31]. Reducing air pollution exposure results in lower CRD morbidity and mortality. Educational interventions have not been fully studied [32]. Pulmonary rehabilitation is effective in COPD [33]. Regular physical activity should be encouraged in these patients. Influenza and pneumococcal vaccinations are recommended for the prevention of COPD exacerbations [25].

\section{Successful interventions in LMICs}

Preventive measures reducing biomass fuel combustion were found to reduce the risk of COPD $[3,34]$.

\section{Community-wide programmes}

Community-wide programmes on COPD control have been started in many countries but definitive results are not yet available [35].

\section{$S D B$}

Successful interventions in developed countries

Active education programmes on diet and exercise are an important component of SDB management [36]. Continuous positive airway pressure is highly effective in obstructive sleep apnoea syndrome (OSAS) and decreases cardiovascular comorbidities [37, 38].

\section{Community-wide programme}

A Finnish national programme has been started for the prevention and treatment of sleep apnoea (2002-2012) [39].

\section{Occupational CRDs}

Pneumoconiosis

Improvement in ventilation and government legislation has dramatically reduced the prevalence of pneumoconiosis in many countries [1] but more data are needed in LMICs.

\section{Occupational asthma in developed countries}

Control of exposure by noxious agent substitution, improvement of ventilation, change in process and enclosure is effective in the primary and secondary prevention of occupational asthma $[40,41]$.

\section{Early determinants of chronic respiratory diseases}

Successful interventions in developed countries

In respiratory distress syndrome of premature infants, surfactant and antenatal steroids [42] have dramatically decreased deaths. Primary prevention of allergy and asthma is still a matter of debate, as only multifaceted interventions have shown some efficacy $[43,44]$. A Finnish national programme associated with the Global Alliance Against Chronic Respiratory Diseases (GARD) has been started for the prevention and treatment of allergy and asthma (2008-2018) [45].

\section{Successful interventions in LMICs}

Reduction of indoor air pollution exposure from biomass fuel use is a potentially important intervention for the prevention of 
acute respiratory infection in children $[46,47]$ but evidence for its impact is lacking [48].

\section{Transverse NCD prevention and control programmes with CRD components}

HCPs face considerable and diverse challenges in LMICs. These include separate, disease-specific interventions fragmenting and duplicating efforts, limiting resources across a range of priorities, as well as competing with programmes against communicable diseases. However, such transverse programmes: 1) may face difficulties in the evaluation of their effectiveness; 2) do not usually provide for adaptation to national, regional, and local needs and resources, resulting in nonfeasibility, nonsustainability or both; 3) do not usually develop a partnership between policy makers and HCPs in the field and, consequently, fail to transform evidence into policies and policies into practice; and 4) do not usually develop and implement affordable educational methods that can be sustained in the resource-poor settings of LMICs.

There are few examples of successful programmes incorporating several NCDs, in some cases with infectious diseases in children and adults [49-51]. Lessons learnt from these initial efforts confirm that such methods may be extended in many LMICs to address priority needs in NCD prevention and management.

\section{Models of risk factor effect and avoidance on CRDs}

There is little systematically collected evidence on the overall contribution of environmental risk factors to the global burden of disease. WHO recently completed a comprehensive, systematic and transparent estimate of the disease burden attributable to the environment, and $24 \%$ of the global burden of disease was estimated to be due to environmental risk factors [52].

The WHO Comparative Risk Assessment methodology [53] enabled the assessment of global mortality and morbidity resulting from exposures to selected occupational hazards in the year 2000. Occupational risk factors were responsible for $13 \%$ of COPD cases, $11 \%$ of asthma cases, $9 \%$ of lung cancer cases, and $100 \%$ of pneumoconioses and mesothelioma cases [54].

Health benefits that environmental interventions could achieve are major considerations when choosing environmental health actions to prevent disease. WHO has released profiles of the environmental burden of disease for 192 countries [55]. 13-37\% of the countries' disease burdens could be prevented by environmental improvements, resulting in a reduction of $\sim 13$ million deaths per yr [56].

For successful NCD prevention and control strategies, a focus on individuals needs to complement population-wide strategies. Strategies that focus on individuals are cost-effective only when targeted at high-risk groups. Tools predicting an individual's absolute NCD risk are vital for targeting limited resources in high-risk individuals who are likely to benefit the most [57]. The WHO/International Society of Hypertension (ISH) charts, already available, enable the prediction of the future risk of heart attacks and strokes in people living in LMICs [57, 58]. Risk charts are also available for cancer [59].

\section{PRIORITISED RESEARCH AGENDA FOR CRDS}

Research opportunities vary between high-income countries, where diagnostic methods and treatments are usually available, and LMICs. The priorities should be flexible enough to harmonise the specific needs and conditions of the countries. Standardised methods, in particular for epidemiologic studies, should be made available and should be tailored for LMICs. The redefining (phenotyping) of CRDs is ongoing and will influence the programme in coming years as well as the transition of disease burden in different regions and climate changes. Dissemination of the relevant information and training of primary health care should be part of the research programme.

Five topics have been prioritised according to short-, mediumor long-term deliverables (table 2) and depending on burden, perceived need in LMICs, potential impact on health and gaps in knowledge, as well as cost-effectiveness and applicability to LMICs as follows. 1) Severe/uncontrolled asthma is a major health problem and interventions seem to be cost-effective, considerably reducing burden and mortality. They should be tested in various settings and comorbidities should be considered. 2) Modelling for estimates of the impact of interventions for prevention of NCD should be envisaged, and risk charts for COPD and OSAS can be developed. 3) The impact of reduction in obesity on the prevention of SDB should be studied as part of the NCD prevention plan. 4) Assessment of patterns of disease and symptoms in adults presenting to firstlevel facilities in LMICs should serve as a guide to the development of transverse programmes. 5) Development and evaluation of transverse (integrated) programmes of prevention and care in selected LMICs with different resources and needs employing methods used in the Practical Approach to Lung Health (PAL) [51], Practical Approach to Lung Health and HIV/AIDS in South Africa (PALSA Plus) [50,60] and other similar programmes. A dominant feature of this programme is the strengthening of health systems through education and the optimal use of resources.

Other interventions should be discussed. Research should be conducted to better appreciate definition, risk factors, burden, prevention and control, and a programme should be started when sufficient knowledge becomes available.

\section{TOPICS FOR FUTURE RESEARCH}

Some CRDs are known to be of great importance, but further studies are needed to fully define their burden and/or the methods needed to be established/validated for their assessment in population-based surveys in LMICs. There is a need for operational research, better surveillance of vital statistics, standardisation of lung function testing in LMICs and estimation of costs of improving management of CRD. Once these methods are clarified, research should start in areas including $\mathrm{SDB}$, bronchietasis and pulmonary hypertension.

\section{SUPPORT STATEMENT}

This paper was proposed as one of the background papers for the WHO meeting on "A Prioritised Research Agenda for Prevention and Control of Noncommunicable Diseases" held in Geneva, Switzerland on August 25-26, 2008. However, the content of this paper does not represent the final outcome of the WHO meeting.

\section{STATEMENT OF INTEREST}

Statements of interest for J. Bousquet, G. Joos, M. Humbert and L.M. Fabbri can be found at www.erj.ersjournals.com/site/misc/ statements.xhtml 
TABLE 2 Research priorities in chronic respiratory diseases (CRDs) from the public health perspective, proposed to focus on low- and middle-income countries (LMICs) but recommended for all countries

\section{1) Severe/uncontrolled asthma} and comorbidities

Gaps in knowledge and gaps in knowledge translation into policies

2) Impact of primary and secondary prevention of CRDs

3) Effectiveness of integrated prevention and management of chronic diseases in PHC in low-resource settings

\section{4) COPD and comorbidities}

Planning management of a person with COPD and concomitant comorbidities (CVDs, diabetes and others)
To reach consensus on a universal definition of severe/uncontrolled asthma in adults and children with identification of gaps in the knowledge

To estimate (and monitor annually) the number of countries with access to spirometry, essential medicines for CRDs and adequate care (common to topics 1, 3, 4 and 5)

To develop models to estimate the regional and global attributable fraction of risk of CRD related to tobacco smoke

solid fuel combustion, outdoor air pollution and allergens, and the potential impact of interventions for their reduction To develop models to estimate the impact of healthy diet and physical activity on prevention and control of obesity and its major comorbidities, such as CVDs, type II diabetes and SDB

To develop models to estimate the impact of early detection of occupational CRDs and subsequent intervention on the prevention of disability due to occupational CRDs To investigate the feasibility, effectiveness and affordability of integrated prevention and management strategies for CRDs, CVDs, diabetes and other priority diseases in PHC in pilot countries. Based on PAL, PALSA Plus, IMAI, $\mathrm{IMCl}$ and other programmes

To investigate the outcomes of a tailored syndromic approach to case management of chronic diseases in PHC by trained nurses with the supervision of physicians in pilot countries using an implementation plan based on PAL, PALSA Plus, IMAI, IMCl and other programmes To estimate (and monitor annually) the number of countries with access to spirometry, essential medicines for CRDs and adequate care

(common to topics 1, 3, 4 and 5)

To reach consensus on a universal definition of COPD, COPD exacerbations and risk factors for exacerbations, and to address gaps in knowledge to understand mechanisms of exacerbations

To propose essential PROs acceptable in all countries

To estimate (and monitor annually) the number of countries with access to spirometry, essential medicines for CRDs and adequate care (common to topics 1, 3, 4 and 5)
To develop and validate, in pilot studies, a protocol to estimate the prevalence, case fatality rate and comorbidities of severe/ uncontrolled asthma

To implement studies in LMICs to confirm the impact of access to ICS on morbidity and case fatality of severe/uncontrolled asthma in children and adults

To develop risk charts for COPD and OSAS using the methodology of WHO CVD risk charts, and to test its usefulness as a tool to change behaviour of health professionals, users of health services and the community

To develop and validate, in pilot studies, simple protocols

(including questionnaires and spirometry) to assess the CRD risks

To assess CRD burden on emergency services and PHC facilities

To develop methods for measurement of the impact of the interventions (e.g. indicators and outcomes for audit and pragmatic randomised controlled trials)

Surveys to assess the COPD prevalence, risk factors and comorbidities (CVDs, cancer and diabetes) in population based studies (BOLD initiative)
To characterise the phenotypes of patients with severe/uncontrolled asthma and search for specific risk

factors and comorbidities

To investigate genomics

To redefine severe asthma phenotypes according to latest research

To review risk charts and assess impact of their adoption on tangible health outcomes

To evaluate benefit of large-scale community education campaigns and community participation in the prevention and control of NCDs (including CRDs) in different cultural and economic settings

Evaluate benefits of treatment on both COPD and all NCDs over treatment of individual diseases, PROs, and specific and general health outcomes, as well as in costs 
TABLE 2 Continued

\begin{tabular}{|c|c|c|c|}
\hline $\begin{array}{l}\text { 5) Early determinants of CRDs } \\
\text { Indoor and outdoor air pollution, } \\
\text { infections, allergens, lack of } \\
\text { awareness and demand to health } \\
\text { services, lack of access to } \\
\text { proper care }\end{array}$ & $\begin{array}{l}\text { To reach consensus on the definition of } \\
\text { major CRDs by age groups, risk factors } \\
\text { and identify gaps in knowledge } \\
\text { Develop methodology for a survey in } \\
\text { LMICs to study prevalence of CRD and } \\
\text { high risk patients in children } \\
<5 \text { yrs of age } \\
\text { To estimate (and monitor annually) the number } \\
\text { of countries with access to spirometry, essential } \\
\text { medicines for CRDs and adequate care } \\
\text { (common to topics } 1,3,4 \text { and } 5 \text { ) }\end{array}$ & $\begin{array}{l}\text { Surveys using spirometry and other } \\
\text { case finding strategies to determine } \\
\text { CRD prevalence (including asthma) in } \\
\text { children and adolescents, and to } \\
\text { identify risk factors in early life } \\
\text { To develop and validate strategies } \\
\text { for the management of acute } \\
\text { respiratory diseases and asthma in } \\
\text { LMICs for children }<5 \text { yrs of age }\end{array}$ & $\begin{array}{c}\text { Birth cohort studies and other } \\
\text { longitudinal studies to assess genetic } \\
\text { and early environmental determinants } \\
\text { on CRD causality (especially asthma) } \\
\text { Develop and evaluate efficacy of } \\
\text { preventive interventions worldwide } \\
\text { and in LMICs }\end{array}$ \\
\hline
\end{tabular}

A global fund for CRD research in LMICs should be developed. PHC: primary health care; COPD: chronic obstructive pulmonary disease; OSAS: obstructive sleep apnoea syndrome; WHO: World Health Organization; CVD: cardiovascular disease; PAL: Practical Approach to Lung Health; PALSA Plus: Practical Approach to Lung Health and HIV/AIDS in South Africa; IMAI: Integrated Management of Adolescent and Adult IIInesses; IMCI: Intergrated Management of Childhood IIInesses; NCD: noncommunicable disease; PRO: patients' reported outcome; BOLD: Burden of Obstructive Lung Disease; ICS: inhaled corticosteroids; SDB: sleep-disordered breathing.

\section{ACKNOWLEDGEMENTS}

The author affiliations are as follows: J. Bousquet (Hopital Arnaud de Villeneuve and INSERM, Montpellier, France), J. Kiley (National Heart, Lung and Blood Institute (NHLBI), National Institutes of Health, US Dept of Health and Human Services, Bethesda, MD, USA), E.D. Bateman (Health Sciences Faculty, University of Cape Town, South Africa), G. Viegi (Consiglio Nazionale delle Ricerche (CNR) Institute of Clinical Physiology, Pisa, and Biomedicine and Molecular Immunology, Palermo, Italy), A.A. Cruz (Faculdade de Medicina da Bahia, Universidade Federal da Bahia, Brazil), N. Khaltaev (Global Alliance Against Chronic Respiratory Diseases (GARD)/Allergic Rhinitis and its Impact on Asthma (ARIA), Geneva, Switzerland), N. Aït Khaled (International Union Against Tuberculosis and Lung Disease, Paris, France), C.E. Baena-Cagnani (Catholic University, Cordoba, Argentina), M.L. Barreto (Instituto de Saude Coletiva, Federal University of Bahia, Salvador, Bahia, Brazil), N. Billo (International Union Against Tuberculosis and Lung Disease, Paris, France), G.W. Canonica (Allergy and Respiratory Diseases, Dept of Internal Medicine, University of Genoa, Genoa, Italy), K.H. Carlsen (Faculty of Medicine, University of Oslo, Oslo, Norway), N. Chavannes (Leiden University Medical Center, Leiden, The Netherlands), A. Chuchalin (Pulmonology Research Institute and Russian Respiratory Society, Moscow, Russia), J. Drazen (Brigham and Women's Hospital, Harvard Medical School, Boston, MA, USA), L.M. Fabbri (Università di Modena e Reggio Emilia, Modena, Italy), M.W. Gerbase (University Hospitals of Geneva, Switzerland), M. Humbert (Université Paris-Sud, Service de Pneumologie, Hôpital Antoine-Béclère, Clamart, France), G. Joos (Ghent University Hospital, Ghent, Belgium), M.R. Masjedi (Shahid Beheshti University of Medical Sciences, Tehran, Iran), S. Makino (School of Medicine, Dokkyo University, Japan), K. Rabe (Leiden University Medical Center, Leiden, The Netherlands), T. To (Child Health Evaluative Sciences, Research Institute, The Hospital for Sick Children, Toronto, ON, Canada), L. Zhi (Chinese Medical Association, Beijing, China).

The following authors are also members of the Global Allergy and Asthma European Network (GA²LEN): J. Bousquet, G. Viegi, G.W. Canonica, K.H. Carlsen, L.M. Fabbri, G. Joos and K. Rabe.

The authors of the draft are grateful for the contributions received from: A. Agusti (Universitat de Barcelona, Barcelona, Spain), I. Ahn (University of California, San Francisco, CA, USA), I. Annesi-Maesano
(Inserm, Paris, France), I. Ansotegui (Viscaya Hospital, Bilbao, Spain), A.K. Baigenzhin (Euro Asian Respiratory Society, Astana, Kazakhstan), A. Ben Kheder (Hôpital A. Mami, Tunis, Tunisia), K.S. Bennoor (National Institute of Diseases of Chest and Hospital, Mohakhali, Dhaka, Bengladesh), N. Berend (Sydney Medical School, Australia), C. Blaisdell (NHLBI, Bethesda, MD, USA), D. Boayke (Noguchi Memorial Institute for Medical Research, College of Health Sciences, University of Ghana, Legon, Accra, Ghana), S. Bonini (CNR, Rome, Italy), L.P. Boulet (Université Laval, Quebec, QC, Canada), P.J. Bousquet (University Hospital, Nimes, France), C.E. Brightling (University of Leicester, Leicester, UK), P.G. Burney (Imperial College, London, UK), A. Bush (Imperial College, London, UK), S. Buist (Oregon Health and Science University, Portland, OR, USA), W.W. Busse (University of Wisconsin Hospital, Madison, WI, USA), P. Camargos (Departamento de Pediatria da Faculdade de Medicina, Belo Horizonte, Brazil), T.B. Casale (Creighton University, Omaha, NE, USA), M. Cazzola (University of Rome Tor Vergata, Rome, Italy), M. Chan-Yeung (University of Hong Kong, Hong Kong, China), C.Y. Chiang (International Union Against Tuberculosis and Lung Disease, Taipei, Taiwan), E. Chkhartishvili (University Hospital, Tbilissi, Georgia), Y.Z. Chen (Clinic and Education Center of the Capital Institute of Pediatrics, Peking, and Center for Asthma Research and Education, Beijing, China), R. Dahl (University Hospital, Aarhus, Denmark), F. De Blay (University Hospital, Strasbourg, France), P. Demoly (University Hospital of Montpellier, INSERM U657, Hôpital Arnaud de Villeneuve, Montpellier, France), H. Douagui (Centre HospitaloUniversitaire de Béni-Messous, Algiers, Algeria), D. Dumitrascu (University of Medicine and Pharmacy IULIU HATIEGANU, ClujNapoca, Romania), D. Enarson (International Union Against Tuberculosis and Lung Disease, Paris, France), J.L. Eiselé (ERS, Lausanne, Switzerland), L.R. Fairall (Cape Town University, South Africa), F. Kauffmann (Inserm, CESP Centre for Research in Epidemiology and Population Health, Villejuif, France), M. Franchi (Associazione Italiana Pazienti BPCO Onlus, Rome, Italy), D. Gail (NHLBI, Bethesda, MD, USA), R. Gerth van Wijk (Erasmus University, Rotterdam, The Netherlands), P. Godard (University Hospital, Montpellier, France), L. Grouse (University of Washington School of Medicine, Seattle, WA, USA), T. Haahtela (Helsinki University, Finland), E. Hamelmann (Ruhr-University Bochum, Germany), P. Hopewell (University of California, San Francisco, CA, USA), P. Howarth (University Hospital, Southampton, UK), O. Kalayci (University 
Hospital, Ankara, Turkey), R. Kauppinen (Finnish Lung Institute, Helsinki, Finland), Y.Y. Kim (Seoul National University Hospital, Seoul, Korea), V. Kolek (Czech Alliance against Chronic Respiratory Diseases, Czech Pneumological and Phthiseological Society, University Hospital, Olomouc, Czech Republic), M. Kowalski (University Hospital, Lodz, Poland), P. Kuna (University Hospital, Lodz, Poland), L.T.T. Le (University of Medicine and Pharmacy, Hochiminh City, Vietnam), E. Lemarié (University Hospital, Tours, France), K. Lodrup-Carlsen (University Hospital, Oslo, Norway), W. McNicholas (University Hospital, Dublin, Ireland), T. Maglakelidze (University Hospital, Tbilissi, Georgia), J.L. Malo (Sacré Coeur Hospital, Montréal, Canada), E. Mantzouranis (University Hospital, Herakelion, Greece), S. Mavale (Children's Hospital, Maputo, Mozambique), Y. Mohammad (Tishreen University School of Medicine, Lattakia, Syria), M. Morais-Almeida (SPAIC, Lisbon, Portugal), J. Mullol (University of Barcelona, Barcelona, Spain), S. Nardini (General Hospital, Vittorio Veneto, Italy), E. Nizankowska-Mogilnicka (University Hospital, Crakow, Poland), P. Noel (NHLBI, Bethesda, MD, USA), K. Ohta (Teikyo University School of Medicine, Tokyo, Japan), P. O'Byrne (McMaster University, Hamilton, ON, Canada), S. Ouedraogo (Centre Hospitalier Universitaire Pédiatrique Charles de Gaulle, Ouagadougou, Burkina Faso), N. Papadopoulos (University Hospital, Athens, Greece), G. Passalacqua (Allergy and Respiratory Diseases, University of Genoa, Genoa, Italy), R. Pawankar (Nippon Medical School, Bunkyo-ku, Tokyo, Japan), R. PerezPadilla (University Hospital, Mexico City, Mexico), T. Popov (Clinic of Allergy and Asthma, Alexander's University Hospital, Sofia, Bulgaria), A. Punturieri (NHLBI, Bethesda, MD, USA), J. Rosado-Pinto (Lisbon, Portugal), E. Rabehevitra (University Hospital, Anatanarivo, Madagascar), M. Salapatas (EFA European Federation of Allergy and Airways Diseases Patients' Association, Brussels, Belgium), B. Samolinski (Medical University of Warsaw, Warsaw, Poland), H.J. Schünemann (McMaster University, Hamilton, ON, Canada), N. Siafakas (University Hospital Heraklion, Greece), F.E.R. Simons (University of Manitoba, Winnipeg, MB, Canada), J.C. Sisul (Sociedad Paraguaya de Alergia Asma e Inmunología, Paraguay Asuncion, Paraguay), R. Smith (NHLBI, Bethesda, MD, USA), U. Solimene (Faculty of Medicine, University of Milan, Italy), T. Sooronbaev (National Centre Cardiology and Internal Medicine, Bishkek, Kyrgystan), M.A. Tag El-Din (Ain-Shams University, Cairo, Egypt), V. Taggart (NHLBI, Bethesda, MD, USA), A. Tsoy (Euro Asian Respiratory Society, Astana, Kazakhstan), M. Twery (NHLBI, Bethesda, MD, USA), A. Valiulis (University Hospital, Vilnius, Lithuania), E. Valovirta (Terveystalo Turku, Finland), C. Van Weel (Radboud University Nijmegen Medical Centre, Nijmegen, The Netherlands), L. Vardy (Health Canada, Ottawa, ON, Canada), G. Weinmann (NHLBI, Bethesda, MD, USA), A. Yorgancioglu (Celal Bayar University, Medical School, Manisa, Turkey), O. Yusuf (The Allergy and Asthma Institute, Islamabad, Pakistan), H. Zar (University Hospital, Cape Town, South Africa), N. Zhong (University Hospital, Ghanzhou, China), T. Zuberbier (Charité, Berlin, Germany).

\section{REFERENCES}

1 Bousquet J, Khaltaev N. Global surveillance, prevention and control of Chronic Respiratory Diseases. A comprehensive approach. www.who.int/gard/publications/GARD\%20Book\%202007.pdf Date last updated: 2007.

2 World Health Organization. Preventing chronic diseases: a vital investment. www.who.int/chp/chronic_disease_report/full_report. pdf Date last accessed: July 10, 2009. Date last updated: October 5, 2005.

3 Torres-Duque C, Maldonado D, Perez-Padilla R, et al. Biomass fuels and respiratory diseases: a review of the evidence. Proc Am Thorac Soc 2008; 5: 577-590.

4 Crummy F, Piper AJ, Naughton MT. Obesity and the lung: 2. Obesity and sleep-disordered breathing. Thorax 2008; 63: 738-746.
5 Bush A. COPD: a pediatric disease. COPD 2008; 5: 53-67.

6 Martinez FD. Genes, environments, development and asthma: a reappraisal. Eur Respir J 2007; 29: 179-184.

7 von Mutius E, Le Souef PN. Early gene-environment interactions: can they inform primary preventive strategies for asthma? Semin Respir Crit Care Med 2007; 28: 255-263.

8 Mendis S, Fukino K, Cameron A, et al. The availability and affordability of selected essential medicines for chronic diseases in six low- and middle-income countries. Bull World Health Organ 2007; 85: 279-288.

9 Ait-Khaled N, Enarson DA, Bissell K, et al. Access to inhaled corticosteroids is key to improving quality of care for asthma in developing countries. Allergy 2007; 62: 230-236.

10 NAEPP (National Asthma Education and Prevention Program). Expert Panel Report 3: Guidelines for the Diagnosis and Management of Asthma. www.nhlbi.nih.gov/guidelines/asthma/asthgdln. htm Date last accessed: July 10, 2009. Date last updated: 2007.

11 Bateman ED, Hurd SS, Barnes PJ, et al. Global strategy for asthma management and prevention: GINA executive summary. Eur Respir J 2008; 31: 143-178.

12 Coffman JM, Cabana MD, Halpin HA, et al. Effects of asthma education on children's use of acute care services: a meta-analysis. Pediatrics 2008; 121: 575-586.

13 Partridge M, Hill SR. Enhancing care for people with asthma: the role of communication, education, training and self-management. Eur Respir J 2000; 16: 333-348.

14 Chaudhuri R, Livingston E, McMahon $\mathrm{AD}$, et al. Effects of smoking cessation on lung function and airway inflammation in smokers with asthma. Am J Respir Crit Care Med 2006; 174: 127-133.

15 Gotzsche PC, Johansen HK. House dust mite control measures for asthma: systematic review. Allergy 2008; 63: 646-659.

16 Wong CM, Lam TH, Peters J, et al. Comparison between two districts of the effects of an air pollution intervention on bronchial responsiveness in primary school children in Hong Kong. J Epidemiol Community Health 1998; 52: 571-578.

17 Ait-Khaled N, Enarson DA, Chiang CY, et al. Management of asthma: a guide to the essentials of good clinical practice. 3rd Edn. Paris, International Union Against Tuberculosis and Lung Disease, 2008.

18 Ait-Khaled N, Enarson DA, Bencharif N, et al. Treatment outcome of asthma after one year follow-up in health centres of several developing countries. Int J Tuberc Lung Dis 2006; 10: 911-916.

19 Ait-Khaled N, Enarson DA. Ensuring the quality of asthma case management. Int J Tuberc Lung Dis 2006; 10: 726-731.

20 Haahtela T, Tuomisto LE, Pietinalho A, et al. A 10 year asthma programme in Finland: major change for the better. Thorax 2006; 61: 663-670.

21 Evans R III, Gergen PJ, Mitchell H, et al. A randomized clinical trial to reduce asthma morbidity among inner-city children: results of the National Cooperative Inner-City Asthma Study. J Pediatr 1999; 135: 332-338.

22 Fischer GB, Camargos PA, Mocelin HT. The burden of asthma in children: a Latin American perspective. Paediatr Respir Rev 2005; 6: 8-13.

23 Franco R, Santos AC, do Nascimento HF, et al. Cost-effectiveness analysis of a state funded programme for control of severe asthma. BMC Public Health 2007; 7: 82.

24 Celli BR, MacNee W. Standards for the diagnosis and treatment of patients with COPD: a summary of the ATS/ERS position paper. Eur Respir J 2004; 23: 932-946.

25 Rabe KF, Hurd S, Anzueto A, et al. Global strategy for the diagnosis, management, and prevention of chronic obstructive pulmonary disease: GOLD executive summary. Am J Respir Crit Care Med 2007; 176: 532-555.

26 Chan-Yeung M, Ait-Khaled N, White N, et al. Management of chronic obstructive pulmonary disease in Asia and Africa. Int J Tuberc Lung Dis 2004; 8: 159-170. 
27 World Health Organization. WHO Report on the Global Tobacco Epidemic. http://whqlib.who.int/publications/2009/9789241563918_ eng_full.pdf Date last updated: 2008.

28 Anthonisen NR, Connett JE, Murray RP. Smoking and lung function of Lung Health Study participants after 11 years. Am J Respir Crit Care Med 2002; 166: 675-679.

29 Kenfield SA, Stampfer MJ, Rosner BA, et al. Smoking and smoking cessation in relation to mortality in women. JAMA 2008; 299: 2037-2047.

30 Menzies D, Nair A, Williamson PA, et al. Respiratory symptoms, pulmonary function, and markers of inflammation among bar workers before and after a legislative ban on smoking in public places. JAMA 2006; 296: 1742-1748.

31 Wipfli H, Samet JM. Global economic and health benefits of tobacco control: part 2. Clin Pharmacol Ther 2009; 86: 272-280.

32 Peytremann-Bridevaux I, Staeger P, Bridevaux PO, et al. Effectiveness of chronic obstructive pulmonary disease-management programs: systematic review and meta-analysis. Am J Med 2008; 121: 433-443.

33 Nici L, Donner C, Wouters E, et al. American Thoracic Society/ European Respiratory Society statement on pulmonary rehabilitation. Am J Respir Crit Care Med 2006; 173: 1390-1413.

34 Chapman RS, He X, Blair AE, et al. Improvement in household stoves and risk of chronic obstructive pulmonary disease in Xuanwei, China: retrospective cohort study. BMJ 2005; 331: 1050.

35 Pietinalho A, Kinnula VL, Sovijarvi AR, et al. Chronic bronchitis and chronic obstructive pulmonary disease. The Finnish Action Programme, interim report. Respir Med 2007; 101: 1419-1425.

36 Davis CL, Tkacz J, Gregoski M, et al. Aerobic exercise and snoring in overweight children: a randomized controlled trial. Obesity (Silver Spring) 2006; 14: 1985-1991.

37 Mansfield DR, Gollogly NC, Kaye DM, et al. Controlled trial of continuous positive airway pressure in obstructive sleep apnea and heart failure. Am J Respir Crit Care Med 2004; 169: 361-366.

38 Drager LF, Bortolotto LA, Figueiredo AC, et al. Effects of continuous positive airway pressure on early signs of atherosclerosis in obstructive sleep apnea. Am J Respir Crit Care Med 2007; 176: 706-712.

39 Laitinen LA, Anttalainen U, Pietinalho A, et al. Sleep apnoea: Finnish national guidelines for prevention and treatment 20022012. Respir Med 2003; 97: 337-365.

40 Juniper CP, How MJ, Goodwin BF, et al. Bacillus subtilis enzymes: a 7-year clinical, epidemiological and immunological study of an industrial allergen. J Soc Occup Med 1977; 27: 3-12.

41 Merget R, Caspari C, Dierkes-Globisch A, et al. Effectiveness of a medical surveillance program for the prevention of occupational asthma caused by platinum salts: a nested case-control study. J Allergy Clin Immunol 2001; 107: 707-712.

42 Engle WA. Surfactant-replacement therapy for respiratory distress in the preterm and term neonate. Pediatrics 2008; 121: 419-432.

43 Asher I, Baena-Cagnani C, Boner A, et al. World Allergy Organization guidelines for prevention of allergy and allergic asthma. Int Arch Allergy Immunol 2004; 135: 83-92.

44 Chan-Yeung M, Ferguson A, Watson W, et al. The Canadian Childhood Asthma Primary Prevention Study: outcomes at 7 years of age. J Allergy Clin Immunol 2005; 116: 49-55.
45 Haahtela T, von Hertzen L, Makela M, et al. Finnish Allergy Programme 2008-2018: time to act and change the course. Allergy 2008; 63: 634-645.

46 Kilabuko JH, Matsuki H, Nakai S. Air quality and acute respiratory illness in biomass fuel using homes in Bagamoyo, Tanzania. Int J Environ Res Public Health 2007; 4: 39-44.

47 Savitha MR, Nandeeshwara SB, Pradeep Kumar MJ, et al. Modifiable risk factors for acute lower respiratory tract infections. Indian J Pediatr 2007; 74: 477-482.

48 Emmelin A, Wall S. Indoor air pollution: a poverty-related cause of mortality among the children of the world. Chest 2007; 132: $1615-1623$.

49 Armstrong Schellenberg JR, Adam $\mathrm{T}$, Mshinda $\mathrm{H}$, et al. Effectiveness and cost of facility-based Integrated Management of Childhood Illness (IMCI) in Tanzania. Lancet 2004; 364: 15831594.

50 Fairall LR, Zwarenstein M, Bateman ED, et al. Effect of educational outreach to nurses on tuberculosis case detection and primary care of respiratory illness: pragmatic cluster randomised controlled trial. BMJ 2005; 331: 750-754.

51 Murray JF, Pio A, Ottmani S. PAL: a new and practical approach to lung health. Int J Tuberc Lung Dis 2006; 10: 1188-1191.

52 Pruss-Ustun A, Corvalan C. How much disease burden can be prevented by environmental interventions? Epidemiology 2007; 18: 167-178.

53 Nelson DI, Concha-Barrientos M, Driscoll T, et al. The global burden of selected occupational diseases and injury risks: methodology and summary. Am J Ind Med 2005; 48: 400-418.

54 Fingerhut M, Nelson DI, Driscoll T, et al. The contribution of occupational risks to the global burden of disease: summary and next steps. Med Lav 2006; 97: 313-321.

55 World Health Organization: The World Health Report 2002: Reducing risks, promoting healthy life. www.who.int/whr/ 2002/en/whr02_en.pdf Date last accessed: July 10, 2009. Date last updated: 2002.

56 Pruss-Ustun A, Bonjour S, Corvalan C. The impact of the environment on health by country: a meta-synthesis. Environ Health 2008; 7: 7.

57 Mendis S, Lindholm LH, Mancia G, et al. World Health Organization (WHO) and International Society of Hypertension (ISH) risk prediction charts: assessment of cardiovascular risk for prevention and control of cardiovascular disease in low and middle-income countries. J Hypertens 2007; 25: 1578-1582.

58 World Health Organization. Prevention of cardiovascular disease: pocket guidelines for assessment and management of cardiovascular risk. www.who.int/cardiovascular_diseases/guidelines/ PocketGL.ENGLISH.AFR-D-E.rev1.pdf Date last updated: 2007.

59 Woloshin S, Schwartz LM, Welch HG. Risk charts: putting cancer in context. J Natl Cancer Inst 2002; 94: 799-804.

60 Bheekie A, Buskens I, Allen S, et al. The Practical Approach to Lung Health in South Africa (PALSA) intervention: respiratory guideline implementation for nurse trainers. Int Nurs Rev 2006; 53: 261-268. 